\title{
“Te sumas?” Entre el espacio literario y el afuera social en algunas novelas españolas del siglo XXI
}

\section{“Are you joining?" Between the Literary Space and Social Outside in Spanish Fictions of 21 st Century}

\author{
Nina Pluta [nina.podleszanska@up.krakow.pl] \\ Uniwersytet Pedagogiczny w Krakowie, Polonia
}

\begin{abstract}
RESUMEN
En el artículo se estudian algunas maneras relevantes de crear, en la narrativa española actual, unidad discursiva entre el espacio social y el ficcional. Los ejemplos proceden de la narrativa de Belén Gopegui, Marta Sanz e Isaac Rosa, autores que representan, a comienzos de este siglo, una tendencia marcada a resituar la narrativa dentro de la coyuntura sociopolítica. A través de una temática de proyección comunitaria y unas situaciones discursivas insólitas, el lector es interpelado a tomar posición en su calidad de ciudadano consciente de los problemas de su tiempo y su reflexión no dista mucho de la que podría emprender fuera de la ficción. La argumentación se encuadra en las concepciones que teorizan la influencia de la literatura en la sociedad y el lector, tales como el cognitivismo, la teoría literaria de orientación marxista o la filosofía de Jacques Rancière y Alain Badiou.
\end{abstract}

\section{Palabras Clave}

Novela española s. XXI; novela social; literatura y política; discurso narrativo; lector-ciudadano

\begin{abstract}
In this paper I point out some relevant procedures used in contemporary Spanish novel in order to unify the fictional and the social discursive universes. Examples have been taken from novels by Belén Gopegui, Marta Sanz e Isaac Rosa, which represent, in current Spanish fiction, a pronounced tendency to connect narrative worlds and the socio-political context. Through a contact with unusual discourse subjects, some of them plural, and through topics related to social and political issues, the reader is spurred on to think over, argue and try out positions as a citizen, in a way that does not substantially differ from what he does in non-literary communication. The line of reasoning is based in theoretical explanations of the literary influence in the reader and the society such as cognitivism, Marxist literary theories and the philosophical thought on literature and politics of Jacques Rancière y Alain Badiou.
\end{abstract}

\section{KEYWORDS}

Spanish Novel $21^{\text {st }}$ Century; Social Novel; Literature and Politics; Narrative Discourse; Citizen Reader 
Si lo de dentro de los libros no tuviera que ver con lo de fuera, la literatura me parecería un soberbio aburrimiento.

(Rafael Chirbes)

Es un hecho avalado por la crítica que en las dos últimas décadas en España han proliferado novelas con una temática que remite a la actualidad sociopolítica: crisis económicas y de la democracia, precariedad y activismo ciudadano global. ${ }^{1}$ Obras de autores como Rafael Chirbes, Belén Gopegui, Isaac Rosa, Marta Sanz, Matías Escalera Cordero, Javier Mestre, Pablo Gutiérrez, Irene Navarro, Cristina Morales, Javier López Menacho se han ganado una notoriedad que en algunos casos se reduce a un reconocimiento minoritario (Menacho, Escalera Cordero), y en otros llega a la consagración a través de los grandes premios de narrativa (Chirbes, Sanz, Morales). Una vertiente igualmente implicada con temas sociales, y que se ha ido intensificando desde el cruce de los siglos, es aquella parte del boom de la memoria que no solo rescata del pasado episodios emocionantes sino que confronta críticamente las versiones oficiales con las silenciadas. Novelas de ambas orientaciones retoman y reelaboran unos asuntos que alimentan hoy los debates sociales en España. Al mismo tiempo resurgen preguntas sobre la incidencia social de la nueva literatura comprometida: ¿en qué medida los textos literarios conforman activamente los debates externos? En paratextos, mesas redondas y entrevistas se nota la urgencia de formular de nuevo los supuestos del compromiso literario ${ }^{2}$, en otras palabras, de las maneras como la literatura se hace presente en la vida social.

Voy a analizar en las obras de algunos de los autores mencionados un tipo de estrategias que modelan una inmersión ficcional híbrida: al lector no solo se le cautiva con unas historias envolventes, sino que al mismo tiempo se lo remite a ciertos asuntos urgentes - sociales y políticos - pendientes de resolución en su comunidad real. Apuntar hacia ese mundo "exterior al libro encuadernado" (Chirbes 2002: 82) y buscar la implicación personal, es lo que ha hecho siempre toda literatura llamada comprometida. La elección y la inscripción del eventual destinatario es en ella crucial; aunque, por cierto, nada puede garantizar que un grupo idóneo de lectores responda al mensaje conscientizador de la obra (Denis 2000: 58-62). Si muchos de los protagonistas novelescos son víctimas de la explotación capitalista, sin voz ni representatividad, al tiempo que los autores de sus historias reciben premios y aumentan su capital cultural, ¿ pueden ambos grupos tener

1 Escalera Cordero, M, (Ed.) (2007), La (re)conquista de la realidad: la novela, la poesía y el teatro del siglo presente, Madrid: Tierradenadie; Florenchie, A. Touton, I., (Eds.) (2011), La ejemplaridad en la narrativa española contemporánea (1950-2010), Madrid-Frankfurt: Iberoamericana-Vervuert; Valle Detry, M. (2013), Por un realismo combativo. Transición política, traiciones genéricas, contradicciones discursivas en la obra de Belén Gopegui y de Isaac Rosa, tesis doctoral, Madrid: UAM; Becerra Mayor, D., (ed.) (2015), Introducción a Convocando al fantasma. Novela crítica en la España actual, Madrid: Tierradenadie Ediciones; Bonvalot, A-L, Rebreyend, A-L, et al. (2019), Escribir la democracia: Literatura y transiciones democráticas, Madrid: Casa de Velázquez; Bonvalot, A-L. (2019), Fictions politiques - Esthétiques de l'engagement littéraire dans l'Espagne contemporaine, Paris: Garnier; Véanse también los números monográficos de revistas: Pasavento (2014), Últimas noticias del realismo en España, A. Florenchie, A. (ed.), núm. 1, vol II; Ínsula. Revista de letras y ciencias humanas, (2016), núm. 835-836, julio-agosto, así como publicaciones colectivas: Becerra, D., Arias, R., Rodríguez Puértolas, J., Sanz, M (2013), Qué hacemos con la literatura, Madrid: Akal; Álvarez-Blanco, P., Gómez L-Quiñones, A. (eds.) (2016), La imaginación hipotecada. Aportaciones al debate sobre la precariedad del presente, Madrid: La Editorial de Ecologistas en Acción; Claesson, Ch. (ed.) (2019), Narrativas precarias. Crisis y subjetividad en la cultura española actual, Gijón: Hoja de lata. Dejo aparte la copiosa producción sobre la literatura de recuperación de la memoria.

2 Aunque la noción se suele repudiar y sustituirse por la de responsabilidad (ver Ruiz Suárez 2016: 55-57; Bonvalot 2019: 341-342) 
en realidad problemas en común? Pese a las incertidumbres, muchos novelistas actuales vienen optando por una comunicación con el lector afín a la tradición brechtiana y basada en poéticas “de interrupción” (Bonvalot 2019: 155 y ss.) y diversas “técnicas de control y persuasión” (Detry 2013: 238-250). Tienen como objetivo practicar quiebres en la realidad ficcional y conectar al receptor con una situación sociohistórica concreta ${ }^{3}$. En los fragmentos que siguen, el lector es reenviado nuevamente hacia su mundo de salida, el no literario. Este efecto se consigue a través de la convocación de unos sujetos discursivos atípicos y la creación de unas situaciones comunicativas que interpelan al que lee en su calidad de "animal social".

Una cosa es afirmar "el papel que la ficción ha jugado desde siempre y sigue jugando como intermediación con la realidad, el poder de la ficción, su capacidad para construir, transmitir, enseñar, una interpretación del mundo" (Rosa 2011: 28), y otra aseverar con firmeza que una novela con temática social y literariamente innovadora puede contribuir a un "debate transformador" (Manifiesto 2012) de la cultura y la sociedad. Esto último tiene algo de arriesgado, de apuesta idealista. Así y todo, los autores que se convocan más adelante, al explicar sus procedimientos artísticos, tienen siempre en mente el aspecto transformador de sus obras (Bonvalot 2109: 338) Aunque dar una respuesta exhaustiva a la pregunta “¿qué hace en realidad la literatura?” desborda los límites de este artículo, no deja de intrigarme la seriedad con que varios escritores españoles se toman hoy el asunto de las "consecuencias de la ficción” (Gopegui 2012a). Para acercarme más al tema, evocaré algunas concepciones teóricas sobre la función cognoscitiva, didáctica y política de la literatura. El espacio mental que surge en lectura, y más aún, la lectura de narrativas que se quieren comprometidas, tiene un carácter proteico, amalgamático, en términos cognitivistas, ya que se debaten en él los mismos temas de economía y política que en los medios de comunicación o en el bar. Analizando las maneras de propiciar deliberadamente esta confusión (o mejor dicho unidad), llamaré conmutadores fictosociales ${ }^{5}$ a los procedimientos narrativos (situaciones discursivas complejas, citas de los discursos sociales, etc.) que hacen casi inoperante la diferencia entre discurso ficcional y discurso de la realidad. En contra de lo que podría esperarse, la mayoría de estos recursos no se infieren de una dominante realista tradicional ${ }^{6}$. Acudiré a algunos conceptos del cognitivismo literario y a aquellos pensadores contemporáneos que redefinen las relaciones entre arte, filosofía y práctica política (Juan Carlos Rodríguez, Jacques Rancière, Alain Badiou, Michael Hard y Antonio Negri).

De la nueva narrativa social, cuyo auge vamos presenciando en España tras la crisis de 2008

3 Numerosos estudios dan cuenta de la orientación brechtiana de, sobre todo, la prosa de Belén Gopegui y de Isaac Rosa. Sobre sus maneras de interpretar el efecto de alienación y distanciamiento, véase, entre otros, Rabanal (2006: 10-11), López (2006: 54-55), Detry (2013: 71-76), Paatz (2017: 339), Bonvalot (2019: 179-182).

4 Gopegui menciona irónicamente la "pretensión inútil y desmesurada de transformar lo que no puede transformarse" (Gopegui 2008: 25). Pero en otra ocasión la ironía desaparece: en la sociedad se dan "tensiones, luchas, que un día se romperán en una u otra dirección, y a la literatura corresponde narrar de qué están hechas, pero al hacerlo se convierte a su vez en parte de esa fuerza, aplicada en una u otra dirección" (Gopegui 2012b).

5 Bonvalot lo llama, en la obra de Alfons Cervera, Belén Gopegui e Isaac Rosa, producción del "efecto-política" (2019: 44).

6 Prácticamente todos los estudiosos del tema, se detienen en los aspectos renovadores del realismo en autores como Gopegui, Rosa, incluso en Chirbes, considerado más tradicional y galdosiano. Se recalcan aquellas estrategias que perturban una inmersión ficcional continuada, los efectos de las metalepsis y la presencia de la autoridad que se yergue detrás de los posicionamientos políticos propuestos (Aiello 2014: 95-97; Bonvalot 2019: 155-186, 325-368; Detry 2013: cap. III y IV) 
y las manifestaciones del 2011, no han desaparecido los protagonistas individuales (Potok 2020: 96-97); no obstante, sus historias se van orientando cada vez más a las transformaciones grupales. Isaac Rosa, Belén Gopegui, Rafael Chirbes, Marta Sanz, Cristina Morales, entre otros, declaran su disidencia respecto a la ideología hegemónica que oculta la lógica de la plusvalía, enmascarándola con ideas como libertad y autorrealización individual. En las declaraciones críticas se reniega de una literatura de "historietas" que ocultan "las conexiones reales entre lo privado y lo público" (Gopegui 2014b: 179). Se culpa a la formación posmoderna de despolitizar a las personas: "esta posmodernidad interminable donde no caben grandes palabras, ni grandes relatos, ni grandes propósitos." (Rosa 2011: 27); "la trampa posmoderna de idolatría del entretenimiento", basada en una "deshonesta ideología que juega a no serlo" (Sanz 2012); los mercados y los medios que "hicieron desaparecer lo verdadero y se apropiaron de lo posible" (Gopegui 2012b). Tal argumentación entronca con un tema clásico de la estética marxista, a saber, con la crítica de la subjetividad supuestamente libre como base de la cultura occidental. Juan Carlos Rodríguez sitúa el ascenso de "yo del hombre nuevo, el sujeto libre" en los albores de la modernidad capitalista, junto con el empuje gradual de la burguesía. Esta "lógica del sujeto" dotado de vida interior, libre en su intimidad y racional en sus actos, se ha perpetuado como universal y eterna en, entre otros, la literatura moderna (Rodríguez 2002: 29-40; 2013: 71-73). Polémicos con esta tradición, y sobre todo con sus derivaciones narcisistas en la literatura supeditada al mercado, varios escritores actuales escogen otro modelo: uno que no sirva a "competir en el mercado de las emociones" sino a "comprender que la existencia es un hecho común y no una rencilla de oficina entre unos cuantos "yoes" dominados por la ansiedad." (Gopegui 2014b: 180). Como veremos más adelante, la dimensión colectiva que busca manifestarse discursiva y narrativamente, involucra al mismo tiempo al receptor en un acto comunicativo diferente al que se realiza en un relato de corte más tradicional. En concreto, el lector es llevado a revisar (o reafirmar) su posición como sujeto social y ciudadano.

Este tipo de narración nace de la fe en la transitividad de literatura y en su "voluntad pública" (Chirbes 2002: 84). De ahí que se reivindique de nuevo el valor cognoscitivo, tan natural para la literatura de las épocas anteriores ${ }^{7}$, y que privilegia, en la comunicación literaria, actividades intelectuales como transmitir, desvelar, enseñar y enseñar a comprender. Cierta retórica pedagógica, que nos ha acompañado siempre en la historia (las numerosas metáforas conceptuales del proceso lectivo, tales como, literatura, magistra vitae, libro-amigo íntimo y consejero, novela-laboratorio de ideas y conductas) ha podido mantenerse solo gracias a la convicción de que los contenidos ficcionales pueden relacionarse con la vida y las prácticas sociales. Si la atención del lector (memoria verbal y no verbal, procesos asociativos, afectos) se concentra en unos problemas que son los mismos que surgen en el contexto social, esto no es un fenómeno meramente retórico ni estético, sino que se activan conocimientos y valoraciones reales ${ }^{8}$. Para el cognitivismo, todas las actividades mentales son, en cierto grado, "literarias": imaginar, comparar, amalgamar imágenes, comprender conceptos, crear mundos es lo que hacemos en el día a día de nuestra vida social (Turner 1996: 5-8). La "disposición mental, representacional, perceptiva o actancial", necesaria para imaginarse

7 En los así llamados regímenes ético y representativo (anteriores, según Rancière, al siglo XIX) era obvio que la obra contenía mensajes útiles para la sociedad (2009b: 24-25).

8 Martha Nussbaum da por sentado que seguir los complicados procesos sicológicos y los dilemas morales de los personajes de la novela decimonónica es un buen ejercicio mental para los que trabajan implementando la justicia. (1997: 38). 
mundos literarios, sería muy parecida a la que adoptamos para interpretar los acontecimientos y actos humanos de la realidad (Schaeffer 2002: 183; Rembowska-Płuciennik 2012: 270-275).

Probablemente no exista pues una separación nítida entre lo que se piensa y sabe fuera de la literatura y dentro de ella. Lo confirma, entre otros, el concepto cognitivista de integración conceptual (blend o mezcla), que caracteriza la mayoría de las actividades mentales de comprensión y verbalización, incluidas las de la lectura de ficciones. La mente crea "realidades" no existentes, que resultan de la fusión de rasgos seleccionados de dos, o más espacios mentales de salida: por ejemplo, de la mezcla de los rasgos que tiene el espacio físico alrededor de la tierra (espacio uno) y del sistema abstracto de una moral religiosa (espacio dos) surge el concepto de "paraíso"9. Las mezclas no se limitan a la información estrictamente empírica ni reparan en las reglas de la lógica, pese a ello, funcionan y potencian el conocimiento en la mayoría de las actividades simbólicas humanas, asimismo en la producción y recepción de la literatura. La experiencia de los fantásticos y ficcionales espacios "mezclados" sirve entonces para la comprensión y resolución de problemas reales. Leer ficciones deja huellas reales y duraderas en los sentimientos, pensamientos y actos humanos ${ }^{10}$ y sí se puede hablar de una transferencia de saberes -opiniones concretas, esquemas de razonamientos, reacciones emocionales- no solo desde la realidad a la obra ${ }^{11}$ sino también desde la ficción hacia la realidad.

Si una novela abunda en referencias a la actualidad sociopolítica, para comprenderla, el lector tiene que aportar sus propios conocimientos sobre esos temas, revisar sus propias creencias, opiniones y estereotipos. Po ende, sus saberes y conocimientos se reorganizan - tiene lugar una modificación que va desde la literatura hacia la realidad. Si, como argumenta Holland, el lector de ficciones literarias aporta sus expectativas y fantasías y pone en movimiento los significados - situándose en una intersección entre el tiempo y una dimensión atemporal, entre el espacio externo e interno - ¿por qué no haría lo mismo al tratar palabras y textos más allá de la lectura (Holland 1997: 204-208)? Del mismo modo, los experimentos sobre la inmersión ficcional demuestran que la experiencia del suspense, las emociones y las expectativas que surgen en la lectura son capaces de alterar la percepción y el conocimiento de la realidad empírica (Gerrig 1996: 71-93, 157-194).

Vamos a señalar entonces algunos recursos de la novelística española actual que permiten activar posturas cognitivas propias para un partícipe consciente de los dilemas que brotan en la esfera social. Cuando en la novela se describe o se habla de la proletarización del mundo del trabajo, el lector puede ensayar modos de enfocar y discutir tal cuestión. Al encontrar, leyendo, razonamientos y argumentos diversos sobre lo que aqueja la sociedad de una época determinada, se oscila, por un lado, entre el pretendimiento ficcional (impersonating, Ryan 1980: 409) o fingimiento lúdico (Schaeffer 2002) - que nos hacen adoptar mentalmente los papeles más diversos - y por otro, la toma de responsabilidad ciudadana que deriva del mero hecho de tener que implicar, en la comprensión del mundo ficcional, nuestras propias evaluaciones de lo sociopolítico. Enfrentado a sus propios problemas sociales que la ficción tematiza, interpelado por unos sujetos discursivos

9 Sobre los mecanismos de la integración cognitiva (blend), ver Fauconnier, Turner, 2002: 17-31, 39-45.

10 “The blended space left its trace on reality" (Turner 1996: 68).

11 Para la creación del mundo ficcional nos inspiramos en el conocimiento del mundo real según la regla de la “desviación mínima” (Ryan 1980: 406). Villanueva generaliza como realismo intencional la actitud del lector de ficciones literarias que tiende a "proyectar su propia experiencia empírica de la realidad sobre la realidad leída" (Villanueva 1992: 143). 
variables, el lector tiene que hacer, para comprender el texto, referencia a sus propios modos de entender, discutir y posicionarse en la actualidad en que vive. Varios recursos de las novelas españolas actuales conmutan estas dos dimensiones: aquella en la que actúa el lector lúdico con aquella otra del ciudadano.

En una entrevista Gopegui representa imaginativamente las marcas que deja la lectura como impulsos que penetran en la materia del cuerpo:

Una imagen mental mueve la sangre y excita un cuerpo, otra imagen produce lágrimas, y una idea, valor en forma de adrenalina. La ficción literaria viaja por las células convertida en impulso eléctrico y si es cierto que la pared real ofrece resistencia mientras que la pared imaginaria la atraviesas como un fantasma, no lo es menos que la máscara ofrece, a su manera, resistencia, y que cuando la realidad nos golpea la evocación de determinadas palabras puede crear una armadura con su dureza particular. (Gopegui 2012b, énfasis mío).

El viaje de una parcela de ficción por la sangre, por retomar la metáfora gopeguiana ${ }^{12}$, puede empezar cuando un tema social candente tratado en la ficción involucra al lector y el espacio ficcional se funde con el real, ya que las emociones, los conceptos y argumentos que aparecen en ambos son parecidos. Podríamos llamar estos eventos de lectura conmutadores fictosociales ${ }^{13}$. Como los signos textuales del realismo (Villanueva 1992: 171-189), estos conmutadores son más eficaces si los problemas sociales evocados en la ficción pertenecen al periodo histórico en que tiene lugar la lectura. Desde luego, la literatura que se satura de motivos sociales y económicos de su época, se arriesga a perder su potencial universalidad (Denis, 2000: 37-40); no obstante, es un precio que los escritores actuales parecen estar muy dispuestos a pagar, a cambio de la oportunidad de manejar en sus obras, ciertas ideas, argumentos o inspiraciones que puedan valerle al lector coetáneo cuando, al decir de Gopegui, "la realidad [lo] golpee".

En lo que sigue vamos a señalar, en una selección de novelas contemporáneas, aquellas configuraciones del discurso narrativo que "cortocircuitan" la diferencia entre el espacio de la ficción y el de la lectura (siendo este una sección del campo literario y a la vez, del mundo social).

\section{Sujetos y pronombres: "busco la intersección contigo, conmigo"}

Uno de los procedimientos frecuentes en la narrativa que encaja en la tendencia social son las metalepsis, la fluctuación de los sujetos y la variación de los contextos discursivos. Los autores echan mano de este tipo de metatextualidad para constituir nuevos sujetos: personas o grupos de personas que tratan de "autoproducirse" (Hardt y Negri 2002: 81) y afirmar su agencia frente al difuso poder global. Así se constituyen, por ejemplo, los sujetos insólitos en la narrativa de Gope-

12 Se impone un imaginario corporal, materialista. Para Chirbes, la nueva mirada propuesta en una novela "en un plazo más o menos largo [...] se filtra por ósmosis en otras obras, e impregna por un complejo sistema de capilares la sensibilidad social." (Chirbes 2012b: 28).

13 Al lado de otros conceptos que tienden puentes entre el discurso literario y social, como mímesis formal (Glowinski), ideosema (Cros) o citas de la realidad inmediata (Schmidt), este pretende dar cuenta de procesos de comprensión dinámicos, durante la lectura y durante la activación de sus huellas mentales en la realidad. 
gui. Individuales o plurales, son portadores de una voz que no resulta decisiva en las sociedades de hoy. En la ficción suelen comentar, desde su perspectiva disidente, la historia de los protagonistas principales, perturbando la comunicación literaria tradicional entre el narrador y el narratario. Los desconcertantes sujetos plurales, de carácter más o menos alegórico y decididamente antirrealistas, se apropian del discurso: la "corporación" en El padre de Blancanieves (2007), un sujeto plural que no obstante reflexiona primera persona sobre las acciones de sus miembros o sobre su propio estatus ${ }^{14}$; el "coro de asalariados y asalariadas de renta media" en Lo real (2000), que se expresa en primera persona plural, brindándole apoyo moral al protagonista justiciero; el ordenador que habla en primera persona singular en Quédate este día y esta noche conmigo (2017) y que resulta más humano que los demás empleados de su empresa. Estas inscripciones de sujetos raros y/o plurales conmueven "nuestra tradicional posición de lectores silenciosos, para aproximarnos a actitudes más cercanas a la literatura compartida o en común" (Bértolo 2018: 94).

No obstante, la dimensión colectiva es imaginable solo en el contexto social, no en el espacio de la lectura íntima. He aquí un ejemplo de cómo el texto avanza hacia este primero. El ordenador de Quédate este día y esta noche conmigo clasifica solicitudes de trabajo, pero se enfrasca en meditaciones sobre el proceso de reclutamiento y, en un arrebato de humanidad, dice haber salvado de la destrucción una solicitud original (escrita a dúo y a mano por los protagonistas Olga y Mateo). Haciendo las veces del editor, incluye en la situación enunciativa a los receptores: "A partir de ahora, cuando diga 'ustedes', no estaré aludiendo a mis superiores sino a ustedes, personas de ahí fuera a quienes he convertido en destinatarias de mis breves palabras y de la misiva de Mateo y Olga" (2017: 13, énfasis mío). A espaldas de una corporación global (se trata de Google) que maneja el grueso de la información accesible y controla las vidas privadas, se establece así una comunicación excepcional entre unos sujetos que se escapan al control de los regidores de los big datas. En esta comunicación subversiva participamos también los que estamos "ahí afuera". Con la mención del espacio exterior al que pertenece el lector se procede a relativizar la frontera ficción-realidad ${ }^{15}$, mientras que el lector deja de ser mayormente narratario y pasa a identificándose con una comunidad externa ("ustedes"), obteniendo acceso a un tipo de enunciados "resistentes" a la ubicuidad de los emporios informativos.

El gesto literario y apelativo, con el refuerzo del deíctico "allí fuera", reenvía al lector al mundo social (conmutador fictosocial): tanto en el espacio literario como fuera de él se hace posible reflexionar sobre la posibilidad de subvertir la hegemonía global del capitalismo; se hace posible, como interpreta la novela Becerra (en la estela de Ranciere), enfrentarse a los dueños de las palabras para "desestabilizar el mundo" y "redefinir los límites de lo posible" (2018:52, 49).

Este tipo de juegos con los deícticos suele propiciar, en las novelas de Gopegui, situaciones en que se produce una mezcla (blend) de lo real y lo ficcional. Varias instancias narrativas, en posición metatextual respecto a la historia principal enuncian sus comentarios desde una perspectiva que

\footnotetext{
14 "Ustedes, sujetos individuales, suelen referirse a mí como asamblea, aunque a veces también me llamen congreso, foro, grupo de grupos, movimiento [...] Un comunicado es de las cosas menos solemnes que podemos emitir. Pero yo me he tomado la libertad de añadirle esta presentación porque los sujetos colectivos nos pensamos a nosotros mismos en singular y tenemos nuestras cosas. Preferencias, ya saben, manías, estribillos que se nos pegan a veces, peculiaridades" (Gopegui 2007: 13).

15 Con lo cual se reavivan los procedimientos autotemáticos propios para la novela anterior a la del s. XIX (desde el Quijote hasta Jacques el Fatalista).
} 
engloba al lector. En Lo real, Irene Arce, la narradora que crea el marco para la historia del héroe (lobo solitario que se enfrenta a la injusticia del capitalismo salvaje), dice: "apenas la hemos oído nunca, creo que nos concierne” (Gopegui 2001: 14, énfasis mío); también el "coro de asalariados y asalariadas de renta media", que comenta en primera persona plural la actuación del protagonista, presenta quejas y reivindicaciones grupales: "nunca tendremos libertad para criticar libremente a nuestros superiores, libertad para tomar lo que nos pertenece” (Gopegui 2001: 19, énfasis mío), En estos casos, el lector es muy susceptible de transformar "nos concierne" en "me concierne": me concierne, al igual que al protagonista y su coro, la falta de perspectivas y la impotencia ante las injusticias sistémicas ${ }^{16}$.

La voz que articula preocupaciones reales de grupos reales, que carecen sin embargo de representación pública fuerte, es concedida en la ficción a seres imposibles (corporación, ordenador, coro), que no poseen "subjetividad” en el sentido propio. Atribuir veleidades y rasgos idiosincráticos a sujetos colectivos ${ }^{17}$, antropomorfizar e individualizar una "corporación" de ciudadanos activistas, hablar en singular o plural de emociones y pensamientos compartidos ${ }^{18}$ se convierten entonces en sendos actos de disidencia literaria, que pretenden desmontar la ideología narcisista de la subjetividad y libertad individual.

Gopegui convierte en práctica literaria la reflexión de pensadores como Rancière, Badiou, Hardt y Negri o, en España, de Juan Carlos Rodríguez, sobre la subjetividad en el arte y la política. La proximidad entre la literatura y la política, según Rancière, consiste en que ambas proceden a una reorganización continua de los espacios de actuación social y de los sujetos que pueden ser percibidos en público. Este "reparto de lo sensible", es decir, de lo que puede ser visto y audible (Rancière, 2011: 12-13), pone en movimiento, tanto en la democracia radical como en la literatura, palabras, textos y cuerpos, otorgando visibilidad y poderes de actuación a sujetos emergentes (Rancière, 2011:20-21). La posibilidad de cambio deriva también del concepto filosófico de acontecimiento de Badiou, pensado para trascender las contradicciones entre lo analítico de las ciencias, lo dialéctico de la política y la práctica vital del individuo que emerge como sujeto (2015: 23-26, 41-47) ${ }^{19}$. En las novelas aquí convocadas, la voz de los sujetos emergentes suena extraña no solo por el artificio literario y los blends novedosos entre lo humano y lo abstracto, sino porque se articulan demandas con poca repercusión en el espacio público.

16 Si bien no se sugiere que todo lector sea representante genuino de la clase media, dada la disolución actual de criterios clasistas nítidos, sí cabe recordar que, históricamente, la literatura en su acepción moderna, y sobre todo el modelo de la novela decimonónica, aún influyente, plegó su discurso al ideario de la clase media (cf. Rodríguez 2013: 69-90).

17 "Los sujetos colectivos se impregnan de aquello que sus componentes o miembros saben, leen y viven Comparto, por otro lado, con los sujetos individuales la inclinación a conmoverme ante lo frágil y, en este sentido, la frágil biología de las algas me enternece y asombra" (Gopegui 2007: 113).

18 Fiel a Brecht, Gopegui exige que la literatura "piense" los sentimientos compartidos, proporcionando así al lector medios de (auto)conocimiento (2005).

19 Para ambos filósofos la práctica política sitúa al sujeto en las dimensiones de lo posible y lo provisional. Partiendo de ahí, los participantes de las performances políticas (por ejemplo, las manifestaciones del 15M) pueden denominarse "pueblo fantástico", sujetos que, como los protagonistas de las ficciones, ensanchan y transforman la realidad (FernándezSavater, 2012). 
Veamos otro pasaje en el que la mezcla del universo creado y el espacio no literario se dinamiza gracias al cambio estilístico y a una marcada fluctuación de los pronombres personales, que van esbozando situaciones discursivas momentáneas. Gopegui acostumbra marcar la transición temática hacia cuestiones más generales y políticas con un lenguaje más figurativo y preñado de emociones e impresiones íntimas. Alex, una protagonista de El comité de la noche, abre la historia hablando de sus condiciones de vida y trabajo precarias en una narración aparentemente realista, pero, gradualmente, el enunciado se va volviendo más presentista y lírico:

La ventana da a las ramas de un almez en una calle estrecha con demasiado tráfico de autobuses. Voy a vivir al otro lado de las ramas y aquí, en cada palabra. Yo ya no necesito un cuarto, y no es que Virginia Woolf no tuviera razón sino que esto es una emergencia, como la risa que se mueve en la fotografía, la época, vivir hoy.

Tengo treinta y tres años, podéis decirme que es la edad más hermosa de la vida y que a partir de ahora la madurez es una obligación, o sólo miedo. En el azúcar blanco de los sobres he visto horror, cristales que me hablaban de mundos fríos, y luego el horror se encarnó y habitó entre nosotros en un sueldo [...] Diréis que me han vencido. Que estoy aquí guardando en las palabras lo que no me dejaron poner fuera, hacer fuera. Pero esto es una tregua y es un manifiesto (Gopegui 2014: 15, énfasis mío).

Desde una narración volcada en lo cotidiano, se pasa a plantear ante un interlocutor plural (podéis decirme, diréis) temas como la madurez y las condiciones sociales de la vida por el conducto del lirismo. Se le impone al lector una realidad social compartida con la protagonista, un conflicto en el que se perfilan unos "ellos" que pueden vencernos y donde es necesario formular "manifiestos" 20 sobre cuestiones que no nos dejan de concernir (despidos, dinero, vivienda, comida). Mientras el texto continúa, la variación de los pronombres personales se va intensificando:

Ahora que todo se puede decir, ahora que ya nombramos: capitalismo, destrucción de los derechos,
patriarcado, explotación, trampas del romanticismo, límites, decrecimiento y hasta lucha de clases:
candil de nieve. Puedo verlo allí, en el punto donde se corta lo que sé con lo que no sé todavía, y
no me escapo de todas esas otras palabras al decirlo sino que busco la intersección contigo, conmigo.
Si lo pronuncio en voz alta nos oigo, como esos coros que surgen cuando quien tiene la guitarra
apaga su voz y sólo toca la música y deja que sea el público quien siga cantando. Candil de nieve
porque, mirad, las metáforas que ya conocemos, las cosas que existen simplemente, como ahora al
referirme a esos coros que se forman cuando el cantante calla, están llenas de significados que tal
vez no queríamos. Oigo cómo se llena el espacio cerrado, en las voces el desmadre, la atención e
ingenuidad de las personas cantando estribillos en un concierto. Sin embargo, no quiero decir, por
ejemplo, que nuestras palabras sean repetición. Ni que necesitemos al cantante para que nos dé la
pauta o que otros convoquen el concierto. Aunque los conciertos sean dulces o salvajes o divertidos
o movilizadores, o todo a la vez, lo que nos está pasando empieza y termina más allá de cualquier

20 En el manifiesto, uno de los géneros del compromiso, se presupone una "comunidad emocional" entre el sujeto discursivo y el destinatario, aunque si este no simpatiza con las ideas propuestas puede convertirse en oponente (Denis 2000: 93-94). 
espacio que clausure el afuera cuando suena la música. Nos pasa a la intemperie. Es en la intemperie donde nos escucho decir: candil de nieve. Cantamos de lo que aún no se entiende pero nos hace latir el corazón (Gopegui: 2014: 16, énfasis mío).

La primera persona narrativa se ha difuminado y proyectado en relaciones multidireccionales: consigo misma, con un "tú", con un "nosotros" del que se siente parte, reservando, sin embargo, también un espacio para sus emociones subjetivas ${ }^{21}$. Tal inestabilidad mantiene en alerta al lector, quien puede irse incluyendo o excluyendo de los "nosotros" consecutivos, sentirse implicado en los imperativos ("mirad") o ir identificando las citas de la realidad (la canción de Pablo Milanés "Candil de nieve", por ejemplo). La confusión de los pronombres y el sesgo político de los temas requiere gran capacidad de concentración. La fusión entre lo literario y lo externo es desencadenada tanto por las citas de otros discursos como por la sucesión de los pronombres personales, que van desplazando la perspectiva por diferentes lugares del blend fictosocial. Esta aparición del plural (de primera o segunda persona) en las novelas estimula un cambio de enfoque del universo ficcional, al igual que cuando el "nosotros" rutinario y poco fiable de los políticos de turno es interceptado por sujetos colectivos emergentes (como en el lema del 15M "no nos representan", donde el nosotros relega a los gobernantes a una tercera persona inactiva, ficticia más que ficcional). Gopegui sigue en este sentido las instrucciones de Brecht sobre el arte épico. Insistir menos en las emociones individuales y más en demostrar las contradicciones internas de la sociedad para desencadenar "el pensamiento público" a través de un "reparto de papeles" que le permitiera al receptor implicarse y comprometerse como miembro de un colectivo (Brecht 1984: 148). La narración que adopta el plural del nosotros o vosotros, o el tú, perturba la posición placentera de oyente singular de historias ajenas y remotas, e interpela discursivamente a un lector que no sólo es parte del público (en el sentido estético), sino es sujeto público (en el sentido político), singular o plural, parte de un colectivo que puede tomar la palabra en el ágora. No solo, pues, el tipo de historias que elige el escritor acarrea consecuencias (Gopegui 2008, 2012a), sino también la gramática: los pronombres, las personas plurales del discurso narrativo pretenden inflexionar las convenciones de lectura, que son, en definitiva, instituciones sociales. Adoptando los modos más propios para los géneros textuales de intervención (manifiesto, panfleto) o del género dramático (coro), Gopegui conecta con la tradición del teatro épico brechtiano, busca la alienación, reanima las dimensiones performativas del texto novelesco y pretende arrancarlo de la pasividad del consumo y contemplación privados.

Se podría objetar, claro está, que la susceptibilidad de un discurso literario de conectar más persuasivamente con la actualidad social del momento caduca rápido con el paso del tiempo. Por cierto, las novelas de la misma Gopegui de las últimas tres décadas, se han ido asociando con las cambiantes circunstancias sociales y las etapas sucesivas en la cultura española: la postransicional (Las esquinas del aire, 1998), la milenarista (Deseo de ser punk, 2009) y la del antiglobalismo y los

21 Díaz de Castro habla de un esparcimiento del “nosotros” (cit. por Detry 2013: 213), a su vez, Detry señala que el pronombre se refiere a grupos cambiantes: un sujeto discursivo plural, que incluye o excluye al lector, los españoles, un sujeto muy general, etc. Cuando en cambio aparece el imperativo de segunda persona singular o plural, se interpela al lector a pensar y a actuar (251-253). En otro orden de cosas, obsérvese la metáfora del concierto que prefigura los efectos pragmáticos del contacto con el arte, aquí en concreto, con la música y las canciones (véase también otra novela de la autora, Deseo de ser punk, 2009). 
movimientos sociales del s. XXI (El padre de Blancanieves, 2007, Acceso no autorizado, 2011, El comité de la noche, 2014). No obstante, las argumentaciones con las que los extravagantes sujetos de sus novelas vienen interpelando a los lectores no han perdido en todo ese periodo - desde el cruce de los siglos hasta hoy - nada de su fuerza persuasiva y esto se debe a que problemas como la crisis de la democracia, la precariedad o la erosión de la solidaridad social no se han visto solucionados ni siquiera parcialmente.

\section{Sanz: nosotros, los muertos}

Rancière se refiere a los discursos literarios como a cuasi-cuerpos, "bloques de palabras que circulan sin padre legítimo que las acompañe hacia un destinatario autorizado” (2009a: 50). El peculiar sujeto que emerge en la novela Pequeñas mujeres rojas de Marta Sanz recoge los discursos dispersos, a veces aún no terminados de verbalizarse coherentemente, de las víctimas de los fusilamientos de la Guerra Civil. Su voz - su historia completa aún por contarse- se hace audible en la ficción, y, por ende, en la interdiscursividad española actual. La voz de los muertos mismos, es decir, de los "incontados" (Rancière 1996: 52-53) en el sentido fuerte, de los "sin" y "cualesquiera" (Bonvalot 2019: 146), es la que domina en el concierto del "orfeón polifónico"22 de la novela.

Sanz interviene con esta novela en el debate de la memoria histórica que desde comienzos de este siglo ha ido alimentando en España una corriente cada vez más caudalosa de producciones artísticas. Pese a lo espinoso del tema, la autora echa mano de su habitual audacia estilística, así como de su habilidad en servirse de convenciones variadas: sátira barroquizante ${ }^{23}$, lo neofantástico, realismo mágico, novela negra y gore, ensayo combativo, manifiesto político. Explota también el tono naturalista, la teatralidad y la ironía, como escapatorias ante el horror. Esta combinación explosiva le permite evitar la sentimentalidad, un rasgo criticado en buena parte de las novelas que reconstruyen los conflictos españoles del s. $\mathrm{XX}^{24}$. La experimentación al borde de lo fantástico e inverosímil, así como un estilo irónico, metafórico y conceptista, no impide, sin embargo, que este texto, así como sus demás novelas, comuniquen una clara intención de autenticidad y de compromiso con la verdad y con los problemas más acuciantes de su época (Simó 2018: 8-11).

La acción se centra en las operaciones paleontológicas y forenses realizadas en la fosa por los voluntarios de una ONG -en particular en la dramática historia de Paula, personaje que reúne los contradictorios rasgos de feminista, activista y víctima- a la vez que se van reconstruyendo las historias de los republicanos fusilados durante la Guerra Civil.

El discurso que engloba y domina todos los demás, constituyendo el horizonte ideológico ${ }^{25}$ de la novela es una voz colectiva, el "nosotros" atribuido a los muertos-vivos. Este sujeto retórico

22 Con esta expresión se autopresenta la novela misma a través de una de sus instancias (327). Todas las citas proceden de la edición de Anagrama (Barcelona) de 2020.

23 Las fusiones de lo material y lo abstracto remiten a la estética barroca. Hay una alusión a Quevedo: “una puesta en abismo, hasta la última partícula de polvo enamorado e inútil.” (80).

24 Comentan los muertos-vivos: "No queremos ser ni la mala ni el malo, ni la buena ni el bueno. No queremos ser un libro ni una favorecedora moda miliciana." (Sanz 2020: 154, énfasis mío). Cf. La crítica del relativismo en la novela de la memoria (Becerra 2015: 207 y ss.) 
plural se individualiza con las menciones de personas concretas, de sus idiosincrasias, detalles del aspecto físico y retazos de biografías: "Nosotros somos el maestro y el destripaterrones, la mujer que no comulgaba, el palomo cojo y el masón y el chico que cantaba 'La Internacional' con el puño en alto". (151) Su voz plantea una visión clara, nada ambigua, de las responsabilidades históricas. Nunca se perdonará a:

los mercaderes $[\ldots]$ los que se mordieron la lengua y $[\ldots]$ los que la tuvieron muy larga, plutócratas, ventajistas, especuladores, estraperlistas, pájaros de mal agüero, los que agacharon el morro, los violadores, nunca perdonaremos a los que les daba lo mismo lo uno que lo otro siempre y cuando ellos se quedasen con la parte de los ángeles y la listeza de los ratones coloraos. (156)

El topos de la vida de ultratumba permite que la verdad sea enunciada por un sujeto que ya no pertenece a este mundo. Una convención de larga data despliega aquí toda su potencia política crítica. De este modo, a través de lo fantástico, se realiza el derecho político a hacerse oír, invalidando los falseamientos ${ }^{26}$ : "no vamos a creer nunca que nosotros, asesinadas y asesinados, no podamos recitar nuestros himnos, fantasías y alabanzas." (332).

Se aplica aquí el esquema cognitivo "eventos son acciones", basado en la experiencia corporal y espacial humana (Turner 1996: 26 y ss.): la vida con sus actividades (acción) es "proyectada" sobre la muerte, fin material del ser humano (evento). Por un lado, los habitantes de la fosa entablan entrañables relaciones mutuas, que consisten, entre otros en fundir sus cuerpos en trance de descomposición ${ }^{27}$; por otro, conversan, juegan a las barajas, aprenden idiomas. Cabe fijarse en algo más, a saber, el peculiar marco (frame) que le da coherencia final o "acabamiento imaginativo" al conjunto de los rasgos seleccionados de la mezcla de los espacios de salida: la vida y la muerte (Fauconnier, Turner 2020: 19, 42-44). El marco lo aportan, en este caso, la actitud compasiva y solidaria de los muertos, que se brindan mutuamente consuelo, apoyo fraterno y cuidado corporal de sus restos, por lo visto "inmortales". Se rescatan así, en la novela, valores que habían sido expulsados del espacio social por la manipulación ideológica del franquismo, que llevó, en palabras de Sanz, al "robo de nuestro lenguaje: solidaridad, compromiso, libertad, igualdad, fraternidad, conciencia crítica, humanidad, humanismo y humanitarismo" (2014: 43).

La situación narrativa impuesta por la primera persona plural modifica el convencionalismo de la perspectiva individual en la recepción lectora. El "nosotros", con referencia fluctuante, como lo hemos visto en la narrativa gopeguiana, por momentos se restringe a los muertos, pero luego se va extendiendo a las familias y a todos aquellos sectores de la sociedad española -incluido el lectorque apoyan las exhumaciones y no aceptan la forma como se habían saldado las cuentas históricas. Termina invadiendo todo el espacio ficcional, englobando otros discursos intradiegéticos, y, a la postre, desbordándose hacia los discursos sociales. De este modo, el efecto de omnisciencia realista de las novelas del s. XIX, es aquí sustituido por el de una omnisciencia fantástica, más subjetiva, en un afán de transgredir la tradición sin renunciar al potencial crítico del realismo.

26 "años y años dentro y fuera de la tierra [...] escuchando historias que convierten en hombres y mujeres a nuestros delatores" (154).

27 "Entrelazamos las hilachas de nuestras musculaturas y trasvasamos nuestros coágulos mediante un sistema de vasos comunicantes. Sexo del bueno. De talón a talón fue pasando la corriente de nuestra energía que, de noche, se escapaba de la tierra como un fogonazo" (198). 
Hacia el final de la novela, se da cabida también a la voz de los intelectuales. Entre los diferentes avatares del sujeto-que-escribe destaca la fugaz aparición de una creadora anónima, la supuesta verdadera autora de la novela ${ }^{28}$. Esta, en las últimas páginas, reorienta el “nosotros" hacia las mujeres en general, aludiendo a la transhistórica violencia de género ${ }^{29}$. Se conecta así, persuasivamente, la violencia perpetrada durante la Guerra Civil con las manifestaciones actuales, a saber, la que atenta contra las mujeres, los menores o los animales.

Los muertos se van convirtiendo, en el curso de la novela, en un elemento activo que interviene en el espacio de los vivos, a saber, de los españoles actuales: impactan no sólo en la memoria y las relaciones de sus propias familias -que reconstruyen y concluyen la biografía de las personas queridas, metonímicamente, a partir de los huesos y objetos- sino también en la conciencia colectiva:

Nos fundimos los unos con los otros y, a la vez, seguimos conservando la individualidad de cada esqueleto. Mientras perdure una sola partícula de lo que fuimos, incluso desde el estado de ceniza o transformados en celuloide, seguiremos hablando [...] Ahora hablamos, un poco abatidos por las circunstancias, desde el nicho en el que por fin nos han metido o desde la vitrina, cerradita con llave, del salón familiar (197, énfasis mío).

Sanz explora en la novela esas otras "formas de existencia" atribuida a los muertos que siguen importando en la vida de los vivos; formas parecidas a la de los entes literarios, artísticos o científicos. Según sus propios registros de verdad, estos muertos se convierten en plenamente reales, pertinentes e influyentes, anudando nuevas relaciones con los vivos y creando una especie de "excedente de existencia" (Despret 2015: 15-17). Para ello tienen que ser recibidos y "localizados" (no solo exhumados) en un medio ambiente favorable, atento y hospitalario (ibid. 2015: 18), que es lo que procuran a duran penas agenciar Paula y otros protagonistas de la novela.

La comunidad emergente de los muertos-vivos es paradójica: fantasmal, pero a la vez muy material por la evidencia física de sus restos y muy presente por la fuerza de los recuerdos de los familiares. Estando siempre "fuera de lugar", este sujeto plural es capaz, en palabras de Fernández-Savater, de incorporarse en cualquier lugar, "como espectros que tienen sus momentos y lugares de aparición." (2012). Ubicuo y abarcador ${ }^{30}$, se proyecta sobre varios espacios y se identifica con aquella parte inquieta del discurso público que busca transformar la historia oficial. Es lícito verlo como una prefiguración del subconsciente colectivo con el que habría que trabajar para conseguir una versión renovada de la historia común: "Lo seguiremos contando para dar fe. - 'No, fe no. Mejor testimonio', no sabemos quién habla, pero sin duda es alguien sabio- de nuestras minusvalías, de peripecias terribles que nunca se deberían repetir." (337, énfasis mío).

28 Simó señala la presencia de motivos autotemáticos -reflexiones sobre textos que se escriben, irrupción de sujetos escribientes- en las novelas de Sanz, lo cual borra los límites ficción-realidad y aproxima los dilemas de ciertos personajes de las opiniones y compromisos de la autora misma (Simó 2018: 11-12).

29 Se mencionan asimismo otros peligros sociales inminentes, p. ej. el advenimiento de los que "se dicen salvadores de la patria", creen en la eficacia del alambre de púas y señalan acusadoramente a las "brujas" y a los "sacrílegos" (338).

30 "Intentamos usar un género inclusivo, ser cosméticamente plurales, animalistas, proteger a los más débiles, porque nosotros también cogimos el palito más corto [...]. Dudamos de poder conseguirlo." (14); "Nosotros, ya exhumados y catalogados [...] desde el fondo de los mares a los que arrojaron nuestras cenizas, aún estamos unidos por un delicuescente cordón umbilical. Por una conexión de Skype ininterrumpida. Ahora sí somos, por fin, seres virtuales" (218). 
La referencia inestable del nosotros empleado por la comunidad de los muertos desenterrados pronombre resulta finalmente representativa para una sociedad atravesada por sus contradicciones y conflictos, en la que lector tiene que reposicionarse:

Una lápida con los mismos apellidos de siempre -Cordero y Beato, Beato y Cordero, Cabrerizo y Ríos, Ríos y Beato- relucirá nueva en el camposanto. Los judíos conversos -los cristianos impecables- cebaron muchos cerdos para regalárselos al cura. Nosotros somos ellos, aunque no nos demos cuenta. Cristianos nuevos, niños y niñas, señoras y señores, gente que quiere olvidar lo que fue porque lo que fue le duele o no le dejan serlo. Gente que olvida para purificarse o porque le falta valor. Hermanos disfrazados entre una multitud de hermanos disfrazados. Dejémoslo estar, hoy, aunque sentimos las tibias más húmedas que nunca, no nos apetece discutir. (19)

Hay un amago de identificación: "somos ellos" -unidos, enfrentados, iguales, diferentes, compartiendo, tal vez, finalmente, tras la exhumación de las víctimas, el mismo cementerio- pero luego, de inmediato, hay rechazo. A “ellos” se los relega a la posición no dialógica del discurso, a la tercera persona, distanciándose, como en un manifiesto. Al lector, si accede a actualizar el texto, no le queda más remedio que atenerse al "nosotros"; de lo contrario recae en el lugar de "ellos", cobardes y conformistas. Bien visto, este "nosotros", sobrenatural y categórico, reivindicativo, y frágil como un sonajero encontrado junto a los despojos, tendrá vida solo si los lectores, ciudadanos revisionistas de la historia partidaria, le conceden parte de su espacio mental y su cuota de voluntad para reconstruir la memoria de todos; desde un compromiso nada ficcional.

\section{Súmate, lector}

La variación de situaciones discursivas, resultado de una considerable ampliación de la metatextualidad, caracteriza asimismo gran parte de las ficciones de Isaac Rosa. Este autor potencia los juegos literarios posmodernos para iluminar y poner en cuestión las prácticas discursivas actuales. Los múltiples narradores, hablantes y discutantes, dispuestos en diferentes niveles narrativos, así como la saturación de la prosa con clichés y ejemplos de manipulaciones ideológicas, conforman un tipo de prosa literaria que invita al lector a observar "cómo se construyen los discursos e imaginarios sociales" (Rebreyend 2011: 59) ${ }^{31}$. En este ejercicio de crítica $^{32}$, la narración se llena de secuencias explicativas y argumentativas, desembocando en géneros híbridos, como en el caso de su más conocida antinovela de la memoria El vano ayer (2004), calificada de "docuficción" (Cruz Suárez, Lauge Hansen 2011: 25, Carcelén 2011: 51-56). Frente al lirismo de Gopegui y el humor transgresivo de Sanz, las características salientes de estilo de Rosa serían la virulencia, el temple polémico y la veta paródica.

Como el recurso de involucrar e incluso textualizar a los lectores es una constante de esta narrativa (particularmente intenso en las primeras novelas de Rosa que abordan la cuestión de

31 Basados en el consenso miedoso, el individualismo narcisista, la política del miedo, el consumo desenfrenado, y otros elementos de la mentalidad neoliberal.

32 "poética de cuestionamiento" (Champeau 2011: 31); "contranarraciones, o sea [...] narraciones oriundas en una lectura crítica de otros discursos o representaciones comunes” (Detry 2013:154, 283-284). 
la memoria), las situaciones enunciativas se hacen complejas. Los lectores participan no sólo como receptores inscritos de antemano en la comunicación sino que se hacen presentes como entes "intrusos", “inquietos" y "rebeldes" (El vano ayer), criticando el proceder del narrador; aunque en última instancia se dirigen, claro, a los que leen en "el afuera" (Cruz Suárez, Lauge Hansen 2011: 25-26) 33 . Durante la lectura es imposible bajar la guardia; hay que orientarse bien en los cambios de voz y las metalepsis, desenmarañar las citas abiertas y encubiertas, ubicarse tácticamente en los sorprendentes marcos "espectaculares" del relato (p. ej. la convención teatral en La mano invisible 2011 o la del proyector de imágenes de velocidad variable en $\mathrm{La}$ habitación oscura 2013). El exigente entramado textual necesita entonces de un lector de los lectores: "lector hermeneuta" (Champeau 2011: 28), lector "cansado", "acosado" y cargado de gran responsabilidad (Ennis 2008: 3, 12).

Veamos unos ejemplos sugerentes en los que la realidad social se le insinúa al destinatario bajo la forma de un acontecimiento preñado de potencia transformadora. Proceden de unos relatos breves recogidos en Tiza Roja $(2020)^{34}$, donde Rosa comenta sobre la marcha temas actuales. Los textos parten de un contexto laboral o familiar rutinario pero la acción va inflexionando la normalidad, $y$, a golpes de lo inesperado o lo grotesco ${ }^{35}$, desemboca en algo nuevo, a menudo esperanzador: la historia de una sirvienta que monta un negocio y controla su sector del mercado, de una tienda que se convierte en casa para los sin domicilio o un dueño de empresa que se pasa del lado de sus trabajadores. Además de ingeniosas, estas situaciones crean una posibilidad de agencia y toma de palabra para unos sujetos ostentosamente antiheroicos: trabajadores, parados, hipotecados que bregan con las dificultades cotidianas. En "Tengan ustedes un buen día", un empleado que viaja en el metro rumbo al trabajo se lanza, movido por un impulso súbito, a enumerar sus penas laborales y los abusos que lo victimizan. Su cantilena se parece a la de otros que piden dinero en las calles, salvo que detalla más la explotación laboral. Aunque no haya buscado notoriedad, su actuación se hace viral en la red y pronto aparecen centenares de imitadores: "un tipo que está harto pero que de repente se pone en pie y lo suelta todo" (Rosa 2020: 46). El arrebato de este protagonista, y otros "acontecimientos" parecidos, provocan una nueva configuración en el entorno social. Las personas adoptan posturas antes inauditas, se enfrentan a sus jefes, toman la palabra. Ocurre "una transformación radical que revela la relación no mediada entre el poder y las subjetividades [gracias a] la incontenible variabilidad temporal del acontecimiento" (Hardt y Negri 2002: 38). El acontecimiento, elevado por Badiou a categoría filosófica, y vinculado con la práctica política, restaura la posibilidad de incidir en el status quo y de repolitizar al sujeto (Rodríguez 2012: 31). En Tiza roja encontramos un repertorio ejemplarizante de situaciones diarias en un país desarrollado, que podrían llevar a un eventual quiebre del orden establecido y una reconfiguración de la jerarquía de los sujetos.

33 El narrador, también textualizado, puede citar in extenso las críticas de sus propios lectores, enfrascarse en polémicas, etc. (Detry 2013: 289-293)

34 Las ficciones breves son una parte menos conocida de su obra. Las de Tiza Roja son una nueva recopilación. Varias se publicaron originariamente en el periódico El Diario (eldiario.es). Previamente el autor había publicado ya cuarenta relatos en La Marea (2013-2016), integrados después en los volúmenes Compro oro, 2013, El puto jefe, 2015, Welcome, 2016. Algunos se repiten en Tiza Roja). Rosa explicita las razones que le hacen concebir este género breve, entre ficcional y periodístico, como instrumento de intervención social (Ruiz Sanz 2016: 56-57).

35 La concepción de la fábula corresponde exactamente al "empuje hasta el límite de lo inverosímil de las situaciones de abuso a que nos someten nuestros empleadores” (Ruiz Sanz 2016: 58). 
Rosa propone, por citar de nuevo a Badiou, unos "estados mentales en que el orden del mundo, las potencias dominantes, no tienen el control absoluto de las posibilidades" (2003: 25). En su tratamiento de los discursos e ideologías estatales y clasistas, su narrativa rechaza el acontecimiento como algo fijo y opta, en cambio, por una escritura performativa y dinámica (Bonvalot 2011: 7). De este modo, el presente se revela en su apertura permanente a una posibilidad, a la intervención de un elemento del azar externo necesario para que el hombre sea convocado a la realidad de lo infinito, es decir, para que se convierta en sujeto (Badiou 2015: 29-36) ${ }^{36}$. Por supuesto, en un texto literario es el autor el que simula la actuación del azar externo y no lo real imprevisible. Así y todo, el efecto retórico que Rosa consigue al fabricar sus sorpresivas peripecias, íntimamente relacionadas con la circunstancia sociopolítica, termina siendo algo que el lector no puede limitarse a vivir sólo en un universo ficcional estrechamente entendido.

Los cortocircuitos entre ficción y realidad más llamativos se producen al final de los relatos, en unos actos de habla equivalentes a pregunta y llamamiento. Son, en concreto, unas maneras cuasi propagandísticas de incluir al lector apelando a su conciencia ciudadana: “ ¿Te sumas?” (Toda esa furia, 21), "Que tengan ustedes un buen día” (Tengan ustedes un buen día, 52), ¿Quieres unirte”? (“Noodles, kebab, sushi, derechos laborales", 254). Se alude abiertamente a la posible postura de activismo. Tanto los deícticos como el valor illocutivo de estos actos "conmutan" lo ficcional y lo real, sugiriendo un espacio de referencia común para los protagonistas y los lectores, donde la crítica se vuelca hacia los mismos problemas sociales. Al ser la cognición un proceso constructivo y la literatura un dominio exclusivo de construcción y comparación de modelos de mundos (Schmidt 1997: 216, 224), es imposible que el lector no conecte sus experiencias vividas y conocimientos adquiridos en la sociedad, con unos problemas similares expuestos en la ficción. Estos actos no son pura persuasión propagandística. No anulan lo literario sino que la amalgaman con lo social. Eagleton afirma provocativamente que "[l]a propaganda no tiene nada de malo siempre que se haga bien", y asegura que no necesariamente "todas las obras comprometidas deban ser estridentes y reduccionistas" (2013: 99-100).

Por otro lado, Rosa activa también los conmutadores fictosociales al citar abundantemente enunciados y giros de la realidad interdiscursiva de su momento histórico, la España del s. XXI. En El País del miedo (2008), el relato de un episodio dramático en la vida de una familia española se combina con fragmentos de carácter más ensayístico sobre el miedo que permea cada vez más el habitus de la clase media. La argumentación se refuerza con citas de discursos sociales, por ejemplo, los consejos del Ministerio del Interior para la seguridad del ciudadano. En semejantes fragmentos, la tercera persona narrativa, focalizada en la conciencia de Carlos, el padre, da paso a un "nosotros" generalizador por cuya mediación se cuelan prejuicios, estereotipos étnicos e ideologemas como ese del Otro peligroso: "violan a nuestras hijas y venden droga barata a nuestros hijos" (Rosa 2008: 36, subrayado mío). Las citas de la realidad propician una actitud crítica y discriminatoria, desde la cual se cotejan y valoran discursos e ideologías (Schmidt 1997: 235; Detry 2013: 285). A efectos de comprensión, el lector entra en el espacio de la interdiscursividad sin reparar en las fronteras entre la ficción y la realidad. Si Cros afirma que el usuario de la lengua, que él llama sujeto cultural, transmite de manera semiconsciente "las particularidades de su inser-

36 Esta apertura del presente a lo subversivo y, a la vez, perfectamente posible, aumenta la potencia transformadora de los relatos mejor que lo harían sus artículos, a veces excesivamente didácticos (Ruiz Sanz 2016: 67). 
ción socioeconómica y sociocultural así como la evolución de los valores que marcan su horizonte cultural" (Cros 2003: 18), momentos como estos - lo saben los seguidores actuales de Brecht - permiten tomar una mayor distancia y alcanzar cierto grado de lucidez respecto a su propia comunidad discursiva. En consecuencia, llevan a formular preguntas como estas: ¿consideramos a otros grupos étnicos peligrosos para el nuestro? ¿con quiénes estamos dispuestos a compartir el espacio cotidiano? ¿con quiénes dejaríamos jugar con nuestros hijos? etc.

Las citas de la realidad acumuladas, que se compaginan bien con la disposición a la parodia y el dialogismo de Rosa, vienen resurgiendo en toda su narrativa. En La mano invisible y La habitación oscura se pone en tela de juicio la violencia sistémica capitalista ejercida sobre los trabajadores (en el nivel metatextual per también en la diégesis misma), se narran las mentalidades desde dentro, se insertan pasajes encubiertos de tratados de economía y política, y, finalmente, se citan los discursos y jergas atribuibles a la generación que prosperó en España en la primera década del siglo y se resintió luego de la crisis de 2008. En La habitación, las veloces enumeraciones se acompasan al modo de funcionamiento del proyector acelerado (convención espectacular), aludiendo a la rápida difusión a nivel global que ha tenido la terminología económica y bancaria en las conversaciones cotidianas de principios del s. XXI:

una amenaza de despido, nóminas atrasadas, un cliente que no pagaba, una subvención con la que ya no se podía contar, las dificultades de un familiar, el cierre de un negocio conocido, una asamblea de barrio, una carga policial, una decisión del Consejo de Ministros. (...) Pablo vaticinaba la caída del sistema financiero y brindábamos por ello" (Rosa 2013: 113).

\section{Conclusiones}

Las "nuevas novelas sociales" fomentan una lectura crítica de la realidad social, amoldando sus historias a los debates candentes de una época de crisis múltiples. Lo hacen, entre otros, reorganizando la comunicación literaria, en la que se desecha la tradicional intimidad del "yo" individual y se apela al espacio comunitario real e histórico. Los autores no parecen preocuparse mucho por evitar la así llamada falacia intencional; al contrario, la valoración que exhala el universo creado no dista mucho de cómo ellos mismos se posicionan, axiológica y políticamente, en la realidad. Del mismo modo que la instancia llamada "narrautor" se interpreta como cercana al autor, responsable de los enunciados metatextuales y de una determinada isotopía axiológica (Detry 2013: 203-205), así el interlocutor de esta narrativa, un narratario implícito o un lector explícitamente interpelado, se tiende a confundir intencionadamente con el lector empírico.

$\mathrm{Si}$, por un lado, las novelas en cuestión "se socializan" a través de temas concretos o matizaciones axiológicas palpables, por otro, no desechan el recurso de la literariedad y la fabulación ingeniosa: recuérdense los sujetos fantásticos tales como un ordenador empático, una "corporación" que usa el "yo" o la voz colectiva de los muertos. No obstante, esa ficcionalidad, si se la entiende como una dimensión de lo real abierta a lo posible y lo contingente, no impide articular reivindicaciones sociales concretas: agencia política para grupos de ciudadanos, humanización de las relaciones laborales o revisión del discurso histórico oficial. Las mezclas imaginativas 
pueden ser inverosímiles en términos empíricos; con todo, las soluciones que proponen, son de lo más posibles y aplicables en lo que es espacio de partida de nuestras ficciones: la realidad social $^{37}$.

Permanece siempre abierta la pregunta de cómo compaginar el valor estético con unas tesis socialmente válidas. Los escritores citados no lo hacen por la vía de un realismo supuestamente objetivista sino buscando choques de perspectivas singulares, incluida la visión de un narrador o varios narradores de ningún modo imparciales. ${ }^{38}$ Las nuevas narrativas críticas en España responden en serio al desafío del hacer, en el siglo XXI, una literatura con consecuencias, por parafrasear a Gopegui. Lo artificioso, lo metatextual, los intensos juegos de inmersión y distanciamiento, la fluctuación de los pronombres: unos recursos eminentemente literarios se ponen al servicio de los que aspiran a transformar los sistemas ideológicos y políticos dominantes en nuestro día a día. La crítica ha captado el fenómeno con denominaciones como: posmodernos "de resistencia" (Lozano Mijares), realistas combativos (Detry), autores de "antinovelas de tesis" (Faaber) o sartreanos contemporáneos (Bonvalot), Mientras tanto, Belén Gopegui, Isaac Rosa y Marta Sanz, junto con un número considerable de otros narradores, se aprestan, cada uno a su manera, a minimizar la brecha entre las historias literarias y la Historia vivida de su época.

\section{Referencias bibliográficas}

VVAA. Manifiesto Congreso de Escritores, Intelectuales y Artistas por el Compromiso. Ateneo de Madrid 2012. https://culturaporelcompromiso.wordpress.com/

Aiello, A. J. (2014). La conquista del aire” de Belén Gopegui: Un discurso narrativo de la Generación de los 90 en España inmerso en las coordenadas de la posmodernidad. Hispania, 97, 1, 91-100.

Badiou, A. (2003). El ser y el acontecimiento. Trad. de R. J. Cerdeiras, A.A. Cerletti, \& N. Prados. Buenos Aires: Manantial.

- (2015). Quel communisme? Entretien avec Peter Engelmann. Montrouge: Bayard.

Becerra, E. (2015). La Guerra Civil como moda literaria. Madrid: Clave Intelectual, 2015.

. (2018). Hacia una redefinición de los límites de los posible: 'Quédate este día y esta noche conmigo' de Belén Gopegui. Ínsula, 857, 49-52.

Bértolo, C. (2018). Tres novelas sobre el dinero y el capital simbólico. In Viceversa. La literatura latinoamericana como espejo. Barcelona: Paso de Barca-Cecal.

Bonvalot, A-L. (2012). Poétique de lévénement et renouvellement de l'écriture engagée: lécriture performative dans le roman en marche d'Isaac Rosa. In M-L Acquier, \& P. Merlo (Eds.), La relation de la littérature à l'événement (XIX-XX siècles) (pp. 103-109) Paris: L’Harmattan.

. (2019). Fictions politiques. Esthétiques de l'engagement littéraire dans l'Espagne contemporaine.

Paris: Garnier.

37 "The truth of an input space can come from a blended space that we do not believe to be true or real" (Turner 1996: 83).

38 Mora lo llama "encarnación lingüística singular" en las novelas del realismo fuerte (2014: 199), y Simó "verosimilitud, naturalidad y autenticidad, entendida ésta como un compromiso moral con la verdad que se quiere representar" (2018: 10). 
Brecht, B. (1984). El proceso de los tres centavos: un experimento sociológico. In W. Hecht (Ed.), El compromiso en literatura y arte. Trad. J. Fornas. Barcelona: Ediciones Península.

Carcelén, J.-F. (2011). Ficción documentada y ficción documental en la narrativa española actual. Ignacio Martínez de Pisón, Isaac Rosa. In G. Champeau, J.F. Carcelén, G. Tyras, \& F. Valls (Eds.) Nuevos derroteros de la narrativa española actual (pp. 51-68). Zaragoza: Prensas Universitarias de Zaragoza. Champeau, G. (2014). Realismo y teatralidad: de Benito Pérez Galdós a Isaac Rosa. Pasavento. Revista de Estudios Hispánicos, II, 1, 11-32.

Chirbes, R. (2002a). El punto de vista. In El novelista perplejo (pp. 69-90). Barcelona: Anagrama . (2002b). El novelista perplejo. In El novelista perplejo (pp. 69-90). Barcelona: Anagrama.

Cros, E. (2003) El sujeto cultural. Sociocrítica y psicoanálisis. Medellín: Fondo Editorial Universidad EAFIT.

Cruz Suárez, J.; \& Lauge Hansen, H. (2011). Literatura y memoria cultural en España. In J. Cruz Suárez, \& J. C. Lauge Hansen (Eds.), La memoria novelada I. Hibridación de géneros y metaficción en la novela espanola sobre la guerra civil y el franquismo (pp. 21-39). Bern: Peter Lang.

Detry, M. (2013). Por un realismo combativo: transición política, traiciones genéricas, contradicciones discursivas en la obra de Belén Gopegui y de Isaac Rosa. Tesis doctoral. Universidad Autónoma de Madrid - Université Francois - Rabelais de Tours. https://repositorio.uam.es/bitstream/handle/10486/661868/ valle_\%20detry_melanie.pdf?sequence $=1$

Despret, V. (2015). Au bonheur des morts. Récits de ceux qui restent. Paris: La Découverte.

Eagleton, T. (2013). El acontecimiento de la literatura. Trad. de R. García Pérez. Barcelona: Península.

Ennis, J. A. (2008). Los lectores de Isaac Rosa. Vías de intervención en un campo saturado . In $I^{\circ}$ Congreso Internacional de Literatura y Cultura Españolas Contemporáneas, 1 al 3 de octubre de 2008, La Plata. www. fuentesmemoria.fahce.unlp.edu.ar/trab_eventos/ev.309/ev.309.pdf

Fauconnier, G.; \& Turner, M. (2002). The Way We Think. Conceptual Blending and the Mind Hidden Complexities. New York: Basic Books.

Fernández-Savater, A. (2012) Política literal y política literaria. Sobre ficciones políticas y 15-M. Interferencias, https://www.eldiario.es/interferencias/ficcion-politica-15-m_132_5503295.html

Gerrig, R. J. (1996). Experiencing Narrative Worlds. On the Psychological Activities of Reading. New HavenLondon: Westview Press.

Gopegui, B. (2001). Lo real. Barcelona: Anagrama.

- (2005). Literatura y política bajo el capitalismo. Guaraguao, 21, 9-20.

. (2007). El padre de Blancanieves. Barcelona: Anagrama.

. (2008). Un pistoletazo en medio de un concierto: acerca de escribir de política en una novela. Presentación de L. Martín-Cabrera. Madrid: Editorial Complutense. . (2012a). Consecuencias de la ficción. https://rebelion.org/consecuencias-de-la-ficcion/ . (2014a). El comité de la noche. Literatura Random House.

. (2014b). Desde dónde escribir. In Rompiendo algo. Prólogo y selección de I. Echevarría. Universidad Santiago de Chile: Diego Portales.

. (2017) Quédate este día y esta noche conmigo. Literatura Random House.

Gopegui, B.; \& Bonvalot, A.-L. (2012b). Un diálogo sobre el poder. Entrevista con Belén Gopegui. Minerva. Revista del círculo de Bellas Artes, suplemento eñe núm. 20.

Hardt, M.; Negri, A. (2002). Imperio. Trad. de A. Bixio. Buenos Aires-Barcelona-México: Paidós.

Holland, N. (1997). Reading and Identity: A Psychoanalytic Revolution. In K.M. Newton (Ed.), Twentieth-Century Literary Theory. London: Palgrave. 
López, F. (2006). De La conquista del aire a Lo real: Belén Gopegui frente a los conceptos de libertad y democracia. Letras Hispanas: Revista de literatura y de cultura, 1, 3, 54-69.

Lozano Mijares, $\mathrm{M}^{\mathrm{a}}$ del P. (2007). La novela española posmoderna. Madrid: Arco/Libros.

Mora, V. L. (2014). La construcción del realismo fuerte en algunos libros de narrativa hispánica actual. Istor: revista de historia internacional, 58, 197-222.

Nussbaum, M. (1997). Justicia poética. La imaginación literaria y la vida pública. Trad. de C. Giardini. Barcelona: Andrés Bello.

Paatz, A. (2017). El dilema del dinero en La conquista del aire (1998) de Belén Gopegui. In S. Hartwig (Ed.), Ser y deber ser. Dilemas morales y conflictos éticos del siglo XX vistos a través de la ficción (pp. 338-339). Madrid-Frankfurt: Iberoamericana-Vervuert.

Potok, M. (2020). Mujer y economía. La "narrativa de la crisis" desde la perspectiva de género. Studia Romanica Posnaniensia, 47, 1, 93-105.

Prentice, D. A.; Gerrig, R. J.; \& Bailis, D. S. (1997), What readers bring to the processing of fictional texts. Psychonomic Bulletin \& Review, 4, 3, 416-420.

Rembowska-Płuciennik, M. (2012). Poetyka intersubiektywności. Kognitywistyczna teoria narracji a proza XX wieku. Toruń: Wydawnictwo Naukowe Uniwersytetu Mikołaja Kopernika.

Rabanal, H. (2011). The Pursuit of Solidarity in Post-Transition Spain. Woodbridge: Tamesis.

Rancière, J. (2009a). El reparto de lo sensible. Trad. de C. Durán, H. Peralta, C. Rossel, I. Trujillo, \& F. de Undurraga. Santiago de Chile: Editorial LOM.

- (2009b). La palabra muda. Ensayo sobre las contradicciones de la literatura. Trad. de C. González. Buenos Aires: Eterna Cadencia.

- (2011). Política de la literatura. Estética y política. Trad. de M. G. Burello, L. Vogelfang, \& J. L. Buenos Aires: Libros del Zorzal.

Rebreyend, A.-L., Deconstrucción del realismo. Paradojas de la metáfora del teatro en El vano ayer de Isaac Rosa. Pasavento. Revista de Estudios Hispánicos, II, 1, 57-76.

Rodríguez, J. C. (2002). De qué hablamos cuando hablamos de la literatura. Las formas del discurso. Granada: De Guante Blanco.

- (2012). Subjetividad y subjetivación en la cultura de hoy (notas sobre Foucault y Heidegger y otras cuestiones anexas. Tropelías. Revista de Teoría de la Literatura y Literatura Comparada,18, 16-35.

- (2013). De qué hablamos cuando hablamos del marxismo. Madrid: Akal.

Rosa, I. (2011). La ejemplaridad hoy: un pacto de responsabilidad con los lectores. In A. Florenchie, \& I. Touton (Eds.), La ejemplaridad en la narrativa española contemporánea (1950-2010) (pp. 26-33). Madrid-Frankfurt: Iberoamericana-Vervuert.

- (2013). La habitación oscura. Barcelona: Seix Barral.

- (2014). El país del miedo. Barcelona: Seix Barral.

. (2020). Tiza Roja. Barcelona: Seix Barral.

Ruiz Sanz, C. (2016). La literatura como acto de intervención social: los cuentos de Isaac Rosa. Siglo XXI. Literatura y Cultura Españolas, 14, 51-68. https://doi.org/10.24197/sxxi.14.2016.51-68

Ryan, M.-L. (1980). Fiction, Non-Factual and the Principle of Minimal Departure. Poetics, 9, 403-422.

Sanz, M. (2012). No tan incendiaria. Cáceres: Periférica.

- (2020), Pequeñas mujeres rojas. Barcelona: Anagrama.

Schaeffer, J.-F. (2002). Por qué la ficción. Trad. de J. L. Sánchez Silva. Madrid: Lengua de Trapo. 
Schmidt, S. J. (1997). La auténtica realidad es que la realidad existe. Modelo constructivista de la realidad, la ficción y la literatura. In A. Garrido Domínguez (Ed.), Teorías de la ficción literaria (pp. 207-239). Madrid: Arco/Libros.

Simó, M. (2018). La realidad y sus representaciones: una aproximación a la poética realista en la obra narrativa de Marta Sanz. In C. Somolinos Molina (Ed.), Escrituras del cuerpo: Marta Sanz. Olivar. Revista de Literatura y cultura españolas, 18, 27, e021. https://doi.org/10.24215/18524478e021

Turner, M. (1996). Literary Mind. New York: Oxford University Press.

Villanueva, D. (1992). Teorías del realismo literario. Madrid: Editorial Biblioteca Nueva. 
